\title{
Invisible Surface Oxygen Vacancies in Thin MgO Film: Impacts on Chemical Activity and Secondary Electron Emission
}

Inga G. Vasilyeva ${ }^{a *}$, Evgeniia S. Vikulova ${ }^{\mathrm{a}}$, Natalia B. Morozova ${ }^{\mathrm{a}}$, Alena A. Pochtar ${ }^{\mathrm{b}}$ Igor K. Igumenov ${ }^{\mathrm{a}}$

${ }^{a}$ Nikolaev Institute of Inorganic Chemistry, Russian Academy of Sciences, Siberian Branch Ac. Lavrentyev ave., 3, Novosobirsk, Russia, 630090

${ }^{b}$ Boreskov Institute of Catalysis, Russian Academy of Sciences, Siberian Branch

Ac. Lavrentyev ave., 5, Novosibirsk, Russia, 630090

*Corresponding author

Fax: (+383) 330-94-89

E-mail: kamarz@niic.nsc.ru 


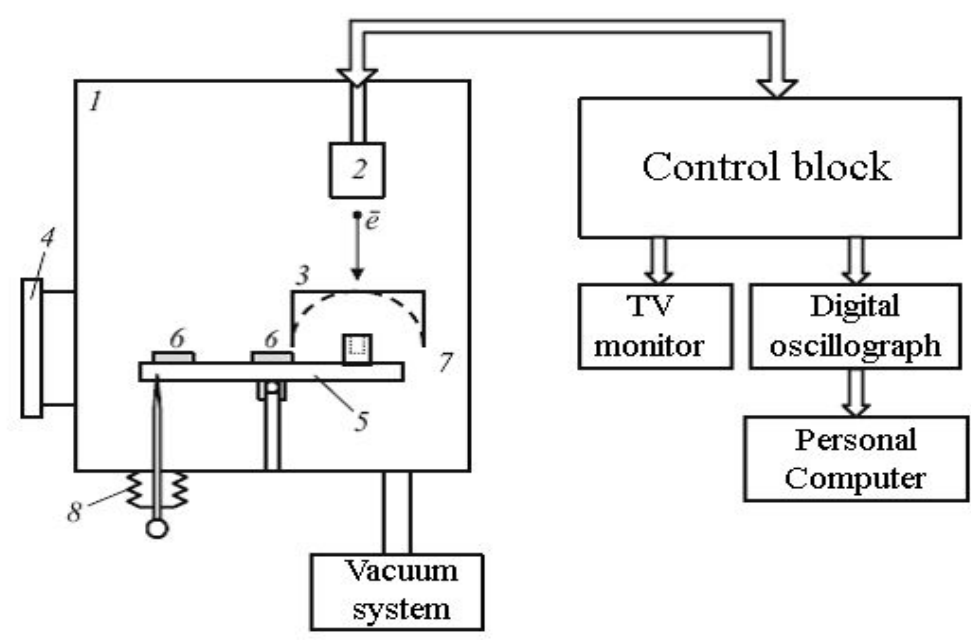

Figure S1. Schematic diagram of secondary electron energy yield measurement 1 - high-vacuum camera; 2 - electron gun; 3 - collector of secondary electrons; 4 - entrance; 5- pedestal for samples; 6 - sample; 7 - Faraday cylinder; 8 - handler

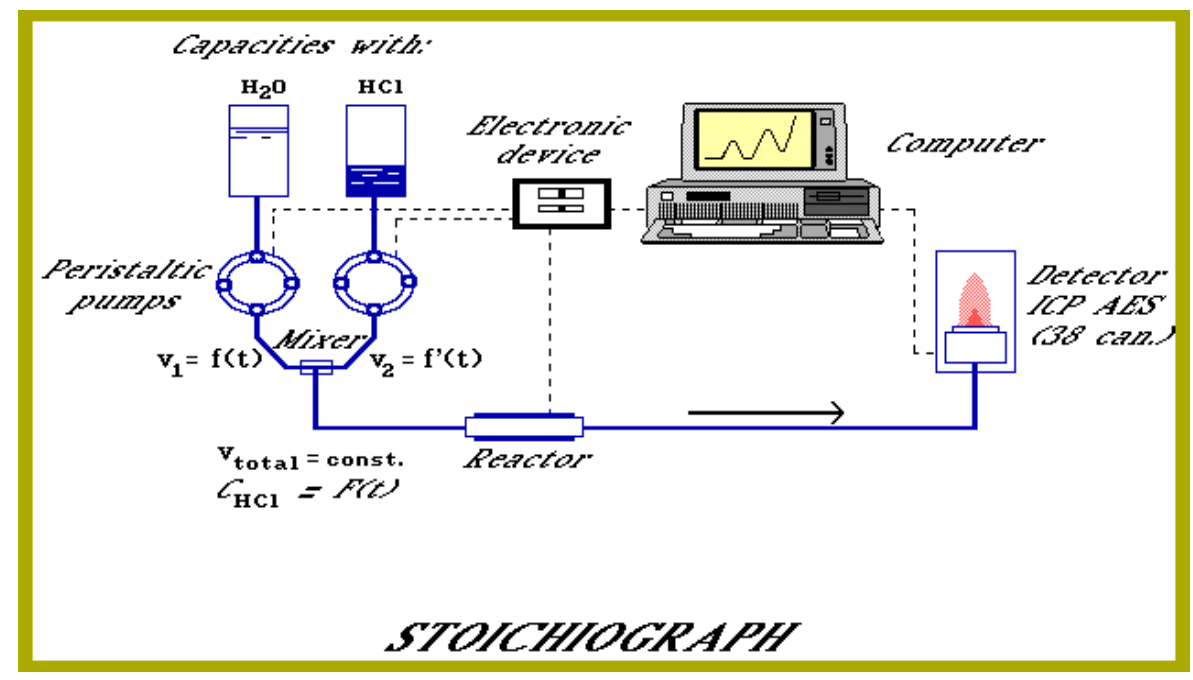

Figure S2. Scheme of stoichiograph

- capacities with $\mathrm{H}_{2} \mathrm{O}$ and HCL solvents to vary the solvent concentration in the desired ratio;

- peristaltic pumps to move the solvent flows with velocities of $\mathrm{v}_{1}$ and $\mathrm{v}_{2}$ into mixer;

- electronic device ensuring a constant volume rate of the mixed solvent with progressively increasing concentration running to reactor;

- reactor with sample;

- analyzer detector as inductively coupled plasma atomic emission spectrometer (ICP AES) with a polychromator;

- computer monitoring and controlling all the system;

- the kinetic curves of dissolution recording continuously and displaying on the screen. 

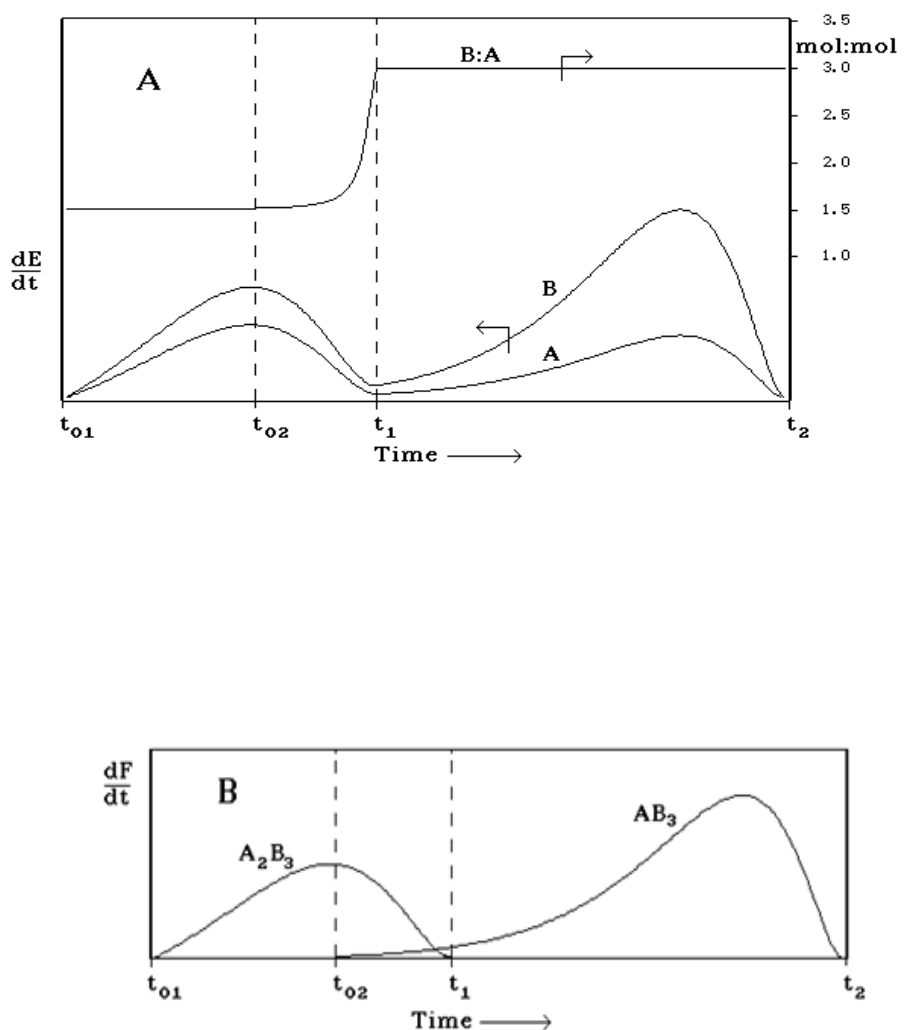

Figure 3S. Differential dissolution in the dynamic regime of the model mixture from two phases $\mathrm{A}_{2} \mathrm{~B}_{3}$ and $\mathrm{AB}_{3}$

A: The kinetic curves of the A and B elements dissolution with variation of masses expressed in $\mu$ mol per unit time $\left(\mathrm{dE} / \mathrm{dt}\right.$ ) versus the dissolution time (bottom) and the stoichiogram $\mathrm{S}_{\mathrm{B}: \mathrm{A}}$ in $\mathrm{mol} / \mathrm{mol}$ versus time; $\mathrm{S}_{\mathrm{B}: \mathrm{A}}=$ constant in the dissolution time $\mathrm{t}_{01}-\mathrm{t}_{02}$ and $\mathrm{t}_{1}-\mathrm{t}_{2}$ being equil to 1.5 and 3 , respectively, $\mathrm{S}_{\mathrm{B}: \mathrm{A}} \neq$ const in the period $\mathrm{t}_{02}-\mathrm{t}_{1}$ with simultaneous dissolution of both the phases (top). The invariance principle of the dissolution stoichiometry is the fundamental property of the stoichiogram of each individual phase of a constant composition, the stoichiogram does not depend on the dissolution conditions and the state of the phase itself.

B: The kinetic curves of the phases dissolution transformed from the kinetic curves for the elements in A; their chemical formula and amounts as the areas under the curves.

\section{Commentary}

The example demonstrates that DD is a standard-free chemical method of the phase analysis as its measuring instruments are calibrated due to standard solutions of elements rather than references of the phases. 


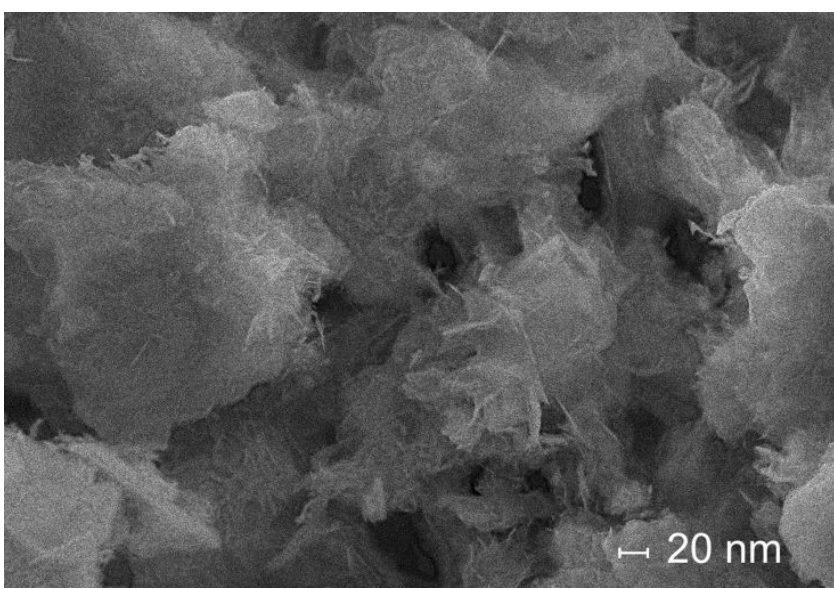

Figure 4S. SEM image of the $\mathrm{C}-\mathrm{MgO}$ powder

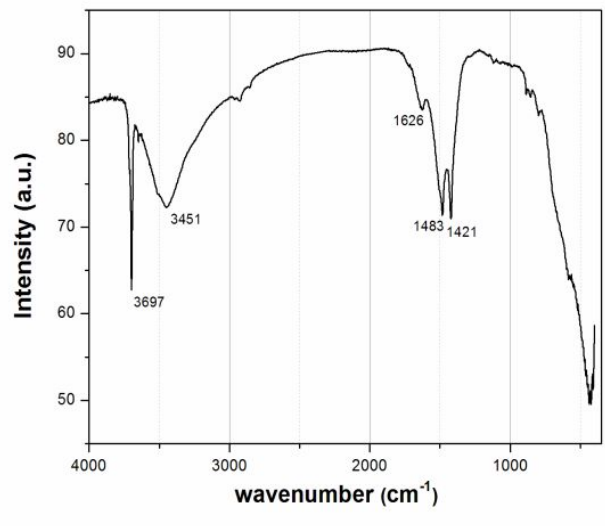

Figure 5S. IR spectrum of $\mathrm{C}-\mathrm{MgO}$ powder

Table 1S Some properties of C-MgO powder

\begin{tabular}{|c|c|c|}
\hline Classification & \multicolumn{2}{|r|}{ Pure for analysis } \\
\hline Composition, mass. \% & $\begin{array}{l}\text { MgO-98; } \\
\text { Cations - } \\
\text { Anions - }\end{array}$ & $\begin{array}{c}\text { water-soluble fraction }-1.5 ; \\
\sum \mathrm{Ca}, \mathrm{Fe}, \mathrm{Al}, \mathrm{Si} \mathrm{I}=0.04 ; \\
\sum \mathrm{Cl}^{\prime}, \mathrm{SO}_{4}^{\prime \prime}=0.07\end{array}$ \\
\hline Surface area, $\mathrm{S} \mathrm{m}^{2} / \mathrm{g}$ & \multicolumn{2}{|r|}{30} \\
\hline The size of crystallites, D nm & \multicolumn{2}{|r|}{ D as $6 / \mathrm{S} \geq 30 \mathrm{~nm}$} \\
\hline
\end{tabular}

